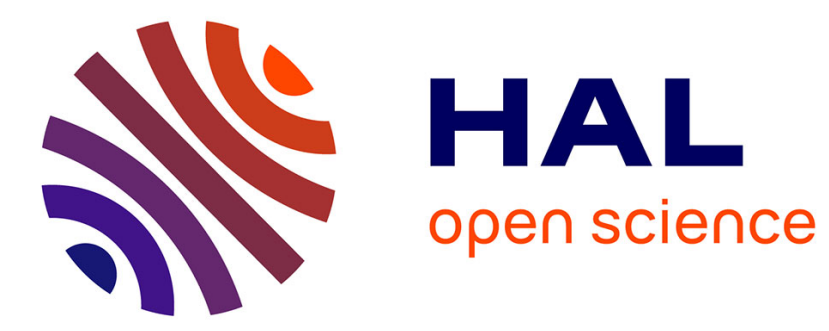

\title{
Exercise-induced changes in hematocrit and hematocrit/viscosity ratio in male rugby players
}

Emmanuelle Varlet-Marie, Jean-Frédéric Brun, E. Raynaud, Christine Fedou

\section{To cite this version:}

Emmanuelle Varlet-Marie, Jean-Frédéric Brun, E. Raynaud, Christine Fedou. Exercise-induced changes in hematocrit and hematocrit/viscosity ratio in male rugby players. Clinical Hemorheology and Microcirculation, 2017, 64 (4), pp.817 - 826. 10.3233/CH-168042 . hal-01804150

\section{HAL Id: hal-01804150 \\ https://hal.umontpellier.fr/hal-01804150}

Submitted on 9 Dec 2019

HAL is a multi-disciplinary open access archive for the deposit and dissemination of scientific research documents, whether they are published or not. The documents may come from teaching and research institutions in France or abroad, or from public or private research centers.
L'archive ouverte pluridisciplinaire HAL, est destinée au dépôt et à la diffusion de documents scientifiques de niveau recherche, publiés ou non, émanant des établissements d'enseignement et de recherche français ou étrangers, des laboratoires publics ou privés. 


\title{
Exercise-induced changes in hematocrit and hematocrit/viscosity ratio in male rugby players
}

\author{
Emmanuelle Varlet-Marie ${ }^{\mathrm{a}, \mathrm{b}}$, Jean-Frédéric Brun $^{\mathrm{c}, *}$, Eric Raynaud de Mauverger $^{\mathrm{c}}$ \\ and Christine Fédou ${ }^{\mathrm{c}}$
}

anstitut des Biomolécules Max Mousseron (IBMM) UMR CNRS 5247, Université de Montpellier, Ecole Nationale Supérieure de Chimie de Montpellier, France

${ }^{\mathrm{b}}$ Laboratoire de Biophysique \& Bio-Analyses, Faculté de Pharmacie, Université de Montpellier, France ${ }^{\mathrm{c}}$ UMR CNRS 9214-Inserm U1046 «Physiopathologie \& Médecine Expérimentale du Cœur et des Muscles - PHYMEDEXP», Unité d'Explorations Métaboliques (CERAMM), Université de Montpellier, Département de Physiologie Clinique, Hôpital Lapeyronie CHU Montpellier, France

\begin{abstract}
We investigated whether the concept of hematocrit/viscosity $(\mathrm{h} / \eta)$ ratio explains the "paradox of hematocrit in athletes", by calculating a "theoretical optimal hematocrit" (i.e., associated with the higher $\mathrm{h} / \eta$ value predicted with Quemada's equation from plasma viscosity, and erythrocyte rigidity index) before and after exercise. 14 rugby players (19-31 yr; weight 65.8-109.2 kg; height 1.7-1.96 m; BMI $21.7-33.1 \mathrm{~kg} / \mathrm{m}^{2}$ ) underwent a standardized submaximal exercise session on cycloergometer corresponding to 225 kjoules over $30 \mathrm{~min}$. The rheologic response to exercise was measured with the MT90 viscometer and the Myrenne aggregometer. After exercise there was an increase in whole blood viscosity $(p<0.05)$ and hematocrit $(p<0.005)$ and a decrease in $\mathrm{h} / \eta$ ratio (from $14.7 \pm 0.34$ to $12.9 \pm 0.37, p<0.005)$. There was an increase in viscometric RBC rigidity indexes "Tk" and "k" in 9/14 subjects. Predicted and actual h/ $\eta$ are fairly well correlated (preexercise $r=0.998, p<0.001$; postexercise $r=0.985 p<0.001$ ) but actual $\mathrm{h} / \eta$ was lower than predicted (preexercise $p=0.005$; postexercise $p=0.02$ ). This discrepancy between predicted and measured hematocrit was not correlated to dehydration or plasma viscosity but was correlated to red cell rigidity $(r=0.774, p<0.01)$ and its exercise-induced change $(r=0.858, p<0.01)$. This study suggests that $\mathrm{h} / \eta$, although it is not directly correlated to parameters of exercise performance, is precisely regulated during exercise according to the classic concept of "viscoregulation", and that the prediction of the theoretical optimal values of $\mathrm{h} / \eta$ and hematocrit by models may help to interpret the actual values of these parameters. However, these models need to be more extendedly tested and improved.
\end{abstract}

Keywords: Blood viscosity, hematocrit, exercise, rugby, erythrocyte deformability

\section{List of symbols}

BMI body mass index

WHR waist-to-hip ratio

RBC red blood cell

SEM standard error on the mean

${ }^{*}$ Corresponding author: Jean-Frédéric Brun, UMR CNRS 9214-Inserm U1046 « Physiopathologie \& Médecine Expérimentale du Cœur et des Muscles - PHYMEDEXP », Unité d'Explorations Métaboliques (CERAMM), Université de Montpellier, Département de Physiologie Clinique, Hôpital Lapeyronie CHU Montpellier, France. Tel.: +33 467338284; Fax: +33 467338986; E-mail: j-brun@chu-montpellier.fr. 


\section{Introduction}

Whether there is an "optimal hematocrit" has been over the last decades a matter of controversy [12]. Since hematocrit is the major determinant of blood viscosity it appeared obvious that excessively high values of this parameter can be associated with a reduction of blood flow $[21,22,38]$ resulting into an impairment in oxygen delivery and thus, presumably, a decrease in exercise performance [4].

An experimental approach of this "Optimal hematocrit" in isolated muscles indicated that, due to reduced vasodilatory reserve in working skeletal muscle compared to resting muscle the optimal hematocrit is shifted to higher values [17].

However a 'paradox of hematocrit in trained athletes' was pointed out several years ago [4]. This paradox is that, on one hand, physiological training decreases hematocrit parallel to increased exercise performance, while on the other hand blood transfusion or erythropoietin (EPO) doping, that both increase hematocrit, are widely used procedures employed for improving performance. Theoretically it should be the opposite and hematocrit-increasing procedures would be expected to impair performance. We proposed to explain this paradox according to percolation theory applied by SchmidSchönbein to blood circulation in muscles [31]. According to this theory, hematocrit has little or no hemodynamic influence in high shear-high pressure conditions (i.e., exercise) explaining that a subject with supraphysiologic hematocrit (e.g.: an EPO doped athlete) may realize outstanding performances, but, in low shear - low pressure conditions (i.e., at rest) it leads to hyperviscosity and impairs blood flow [18].

Furthermore it has been shown that the body can cope with hypererythrocythemia via an homeostatic phenomenon that implies a decrease in red cell rigidity [40]. To what extent this mechanism is efficient in humans is not known.

The most classical way to delineate the positive from the negative effect of hematocrit on circulation and oxygen supply is to calculate the $\mathrm{h} / \eta$ ratio as proposed by the pioneers of hemorheology, S. Chien [8] and J. Dormandy [16] and later popularized by J.F. Stoltz [35]. According to this author "blood's overall oxygen transport capacity is proportional to the ratio hematocrit/blood viscosity."

A recent assessment of the validity of this concept was provided by Stark and coworkers [33] who systematically used the various published formula describing the dependence of viscosity on hematocrit. They evidenced a good agreement between theoretical and observed values.

Over the last years the interest for the $\mathrm{h} / \eta$ ratio has been renewed by some interesting studies $[9,10,25]$.

Since classical equations of blood viscosity such as Quemada's or Dintenfass's ones [13, 27] are known to provide a quite precise model of the influence of factors of viscosity on whole blood viscosity, we used them as a physiological model to investigate viscosity and $\mathrm{h} / \eta$ ratio in athletes at rest and after exercise. More precisely we aimed at predicting in athletes which would be the optimal hematocrit value (i.e, associated with the higher $\mathrm{h} / \eta$ value) before and after exercise, and to compare these predicted values to the actual ones. For this purpose we used Quemada's equation of viscosity that describes viscosity as a function of plasma viscosity, hematocrit, and erythrocyte rheology (i.e., at high shear rate, rigidity) and introduced in it the actual values of plasma viscosity and erythrocyte rigidity with various values of hematocrit.

\section{Subjects and methods}

\subsection{Study subjects}

We used the database of a previous paper in order to test this prediction of hematocrit [2]. Subjects used in this study were 14 male rugby players submitted daily to a physical training program. Their 
main age was 19-31 yr; their main weight was $65.8-109.2 \mathrm{~kg}$; their mean height was $1.7-1.96 \mathrm{~m}$. Their mean waist-to-hip ratio (WHR) was $0.92+0.02$.

They underwent a standardized submaximal exercise session on cycloergometer corresponding to 225 kjoules over $30 \mathrm{~min}$. Pedal speed was kept constant at $60 \mathrm{rpm}$ by the subjects. Dehydration was evaluated by precision weighing (Sartorius model F 150-S-F2, France).

\subsection{Bioelectrical impedance measurements}

Prior to the exercise-test, subjects' body composition was assessed with bioimpedance analysis with a six terminal impedance plethismograph BIACORPUS RX 4000 Biacorpus RX4000, (Healthnesslink, 8 avenue Jean-Jaurès 92130 Issy-les-Moulineaux, France) with data analysis with the software BodyComp 8.4. This device measures total resistance of the body to an alternative electric current of $50 \mathrm{kHz}$ $[5,20]$. Body fat mass, fat-free mass were calculated in each segment of the body according to manufacturer's database-derived disclosed equations, and total water with published equations using the classical cylindric model and Hanai's mixture theory [23].

\subsection{Hemorheological in vitro measurements}

Blood samples for hemorheological measurements $(7 \mathrm{ml})$ were drawn with potassium EDTA as the anticoagulant in a vacuum tube (Vacutainer). Viscometric measurements were done at very high shear rate $\left(1000 \mathrm{~s}^{-1}\right)$ with a falling ball viscometer (MT 90 Medicatest, F-86280 Saint Benoit) [1, 14]. The coefficient of variation of this method ranged between 0.6 and $0.8 \%$. With this device we measured apparent viscosity of whole blood at native hematocrit, plasma viscosity, and blood viscosity at corrected hematocrit (0.45) according to the equation of Quemada [27]. Dintenfass' 'Tk' index of erythrocyte rigidity was calculated [13]. RBC aggregation was assessed with the Myrenne aggregometer [30] which gives two indices of RBC aggregation: ' $M$ ' (aggregation during stasis after shearing at $600 \mathrm{~s}^{-1}$ ) and 'M1' (facilitated aggregation at low shear rate after shearing at $600 \mathrm{~s}^{-1}$ ). The $\mathrm{h} / \eta$ ratio, an index of oxygen supply to tissues, was calculated according to Chien [7] and Stoltz [34] with hematocrit (as percentage) divided by viscosity at high shear rate determined as described above.

The SEFAM aggregometer was used for a more precise assessment of RBC aggregation. This device is based upon the experiments of Mills [24, 32] on cell disaggregation behavior in shear flow. This device measures the changes in backscattered light which are observed when sheared RBC suspensions are abruptly brought to a full stop. The decrease in the optical signal reflects the formation of RBC aggregates $[6,15,26]$. Some parameters are derived from the curve of light intensity as a function of time. The aggregation time is the reciprocal of the initial slope (calculated between 0.5 and $2 \mathrm{sec}$ after the shear has stopped). The aggregation index at $10 \mathrm{sec}$ is a measurement of the extent of erythrocyte aggregation and is the relative surface area above the curve calculated over the first 10 seconds. This device measures also disaggregation thresholds, by submitting blood to a succession of shear rates from $600 \mathrm{~s}^{-1}$ to $7 \mathrm{~s}^{-1}$. The total disaggregation threshold is the shear rate below which the backscattered light intensity starts to decrease, indicating that the shear stress applied to aggregates is no longer sufficient for allowing complete dispersion of RBC aggregates. The partial disaggregation shear rate is defined as the shear rate corresponding to the intersection point of the two asymptotes drawn from the extremes (maximum and minimum shear rate).

\subsection{Blood lactate}

Lactate was assayed with a kit from DuPont specially adapted to the DuPont de Nemours automatic clinical analyzer. This assay was based on NADH production by rabbit lactate dehydrogenase. Coefficients of variation range between 0.7 and $5.6 \%$. 
Table 1

Reformations (mean + SEM) of rheologic parameters during maximal exercise in study subjects

\begin{tabular}{lcc}
\hline & before exercise & after exercise \\
\hline Blood viscosity & $2.9+0.07$ & $3.66+0.17^{* * * *}$ \\
Corrected viscosity $\eta_{45}$ & $3.08+0.09$ & $3.44+0.09^{* * *}$ \\
Plasma viscosity & $1.34+0.01$ & $1.45+0.01^{* * *}$ \\
"Tk" (RBC rigidity) & $0.62+0.01$ & $0.65+0.02^{* * *}$ \\
h/ $\eta$ ratio & $0.15+0.004$ & $0.13+0.004^{* * * *}$ \\
Hematocrit (\%) & $42.64+0.94$ & $46.5+1.09^{* * *}$ \\
RBC aggregation 'M' & $4.3+0.45$ & $4.55+0.37$ \\
RBC aggregation 'M1' & $8.08+0.6$ & $8.12+0.65$ \\
Aggregation time (TA) & $2.77+0.28$ & $1.85+0.14^{* * *}$ \\
Aggregation time (Tf) & $39+2.9$ & $28.6+2.7^{* * *}$ \\
\hline
\end{tabular}

${ }^{*} p<0.05 ;{ }^{* * *} p<0.01 ;{ }^{* * * *} p<0.0001$.

\subsection{Changes in plasma volume}

A formula for calculating plasma volume changes $(\% \Delta \mathrm{PV})$ during exercise from hematocrit changes has been published by investigators of the NASA-Ames Research Center [11, 19, 39] who demonstrated its validity in moderate as well as maximal exercise. We applied this formula to our data. The equation is:

$$
\% \Delta \mathrm{PV}=100 /(100-\mathrm{Ho}) \times 100[(\mathrm{Ho}-\mathrm{H}) / \mathrm{Ho}]
$$

where Ho is resting hematocrit and $\mathrm{H}$ hematocrit during exercise.

\subsection{Statistics}

Results are presented as mean + the SEM. A value of $p<0.05$ was considered as significant. Comparisons were made with nonparametric tests. Correlations were tested by least square fitting for linear, exponential, logarithmic and power relationships.

\section{Results}

Table 1 shows the main hemorheologic changes observed in study subjects before and after exercise. In responses to exercise, a $36 \%$ increase in blood viscosity $(p<0.01)$ was observed, due to a rise in hematocrit $(p<0.005)$, plasma viscosity $(p<0.01)$, and red blood cell rigidity $(p<0.02)$. There was an increase in viscometric RBC rigidity indexes "Tk" and "k" in $9 / 14$ subjects. After exercise there was also a decrease in hematocrit/viscosity ratio (from $14.7 \pm 0.34$ to $12.9 \pm 0.37 p<0.005$ ). Dehydration, evaluated by precision weighing, resulted in a loss of 360 to $973 \mathrm{~g}$ water i.e. 1.69 to $4.32 \mathrm{~g} / \mathrm{kjoule}$. This loss of water is not correlated to plasma volume contraction as assessed by the equation of Greenleaf.

The curve of theoretical optimal $\mathrm{h} / \eta$ plotted $v s$ hematocrit was reconstructed with Quemada's equation. The hematocrit corresponding to the top of this curve was considered as the "theoretical optimal hematocrit".

Figure 1 shows the reconstructed curve of this theoretical optimal $\mathrm{h} / \eta$ plotted $v s$ hematocrit with the actual individual experimental points. It can be seen that on the whole there is a good agreement 


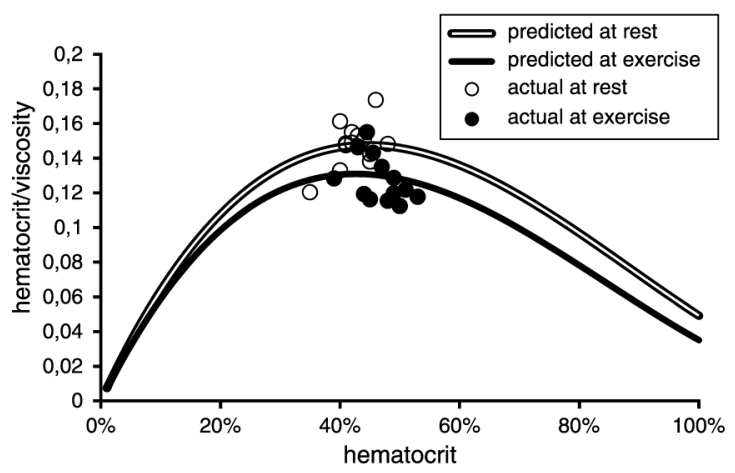

Fig. 1. Comparison between reconstructed curve of the theoretical optimal $\mathrm{h} / \eta$ plotted $v s$ actual hematocrit at rest and the reconstructed theoretical curve after exercise, with actual values of $h$ and $h / \eta$ for each subject. Postexercise reconstructed curve is significantly lower compared to the curve reconstructed from values measured at rest $(p<0.001)$.

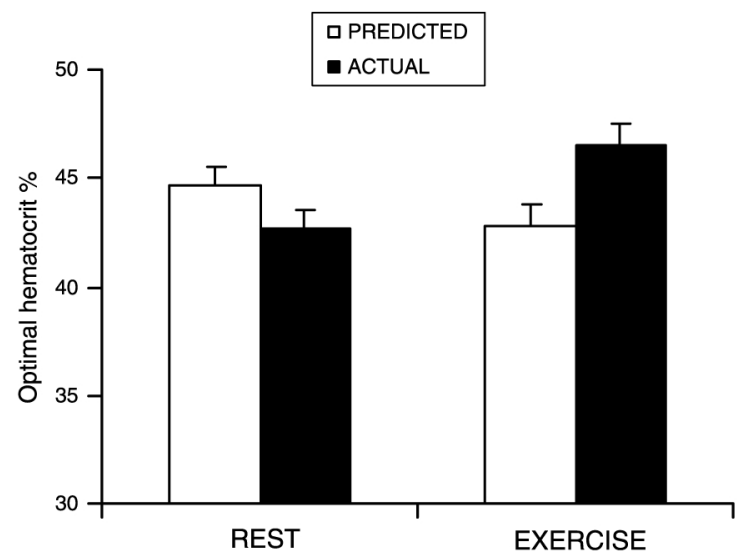

Fig. 2. Comparison between actual hematocrit and predicted hematocrit at rest and after exercise. The difference between actual and predicted is significant in both situations and there is also a significant difference between the mean of the difference at preexercise and the mean of the difference at postexercise $(p=0.005)$.

between the theoretical prediction of $\mathrm{h} / \eta$ and the value of $\mathrm{h} / \eta$ that is actually measured in true life in athletes.

However, as shown on Fig. 2, actual hematocrit was lower than predicted hematocrit at rest $(p=0.0142)$ and was higher after exercise $(p=0.03)$.

As shown on Fig. 3, predicted and actual $\mathrm{h} / \eta$ are fairly well correlated (preexercise : $r=0.998$ $p<0.001$; postexercise $r=0.985, p<0.001$ )]. However as shown on Fig. 4 , actual $\mathrm{h} / \eta$ was lower than predicted $\mathrm{h} / \eta$ (preexercise $p=0,005$; postexercise $p=0,02$ ).

As shown on Fig. 5, the discrepancy between predicted and measured hematocrit was not correlated to dehydration or plasma viscosity but was correlated to red cell rigidity $(r=0.774, p<0.01)$ and its exercise-induced change $(r=0.858, p<0.01)$.

As shown on Fig. 6, these discrepancies between predicted and measured hematocrit were correlated to red cell rigidity $(r=0.774, p<0.01)$ and its exercise-induced change $(r=0.858, p<0.01)$. By contrast they were not correlated to dehydration ( $r=-0.205 \mathrm{NS}$ ) or plasma viscosity $(r=-0.171 \mathrm{NS})$. 


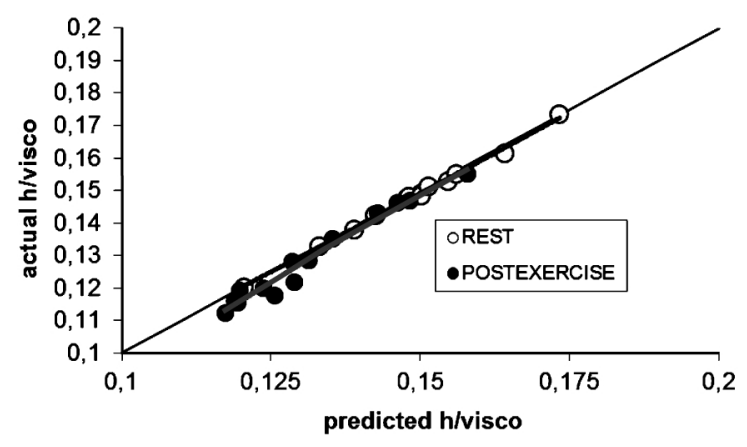

Fig. 3. Correlation between predicted and actual $\mathrm{h} / \eta$. preexercise $(r=0.998, p<0.001)$ postexercise $(r=0.985, p<0.001)$.

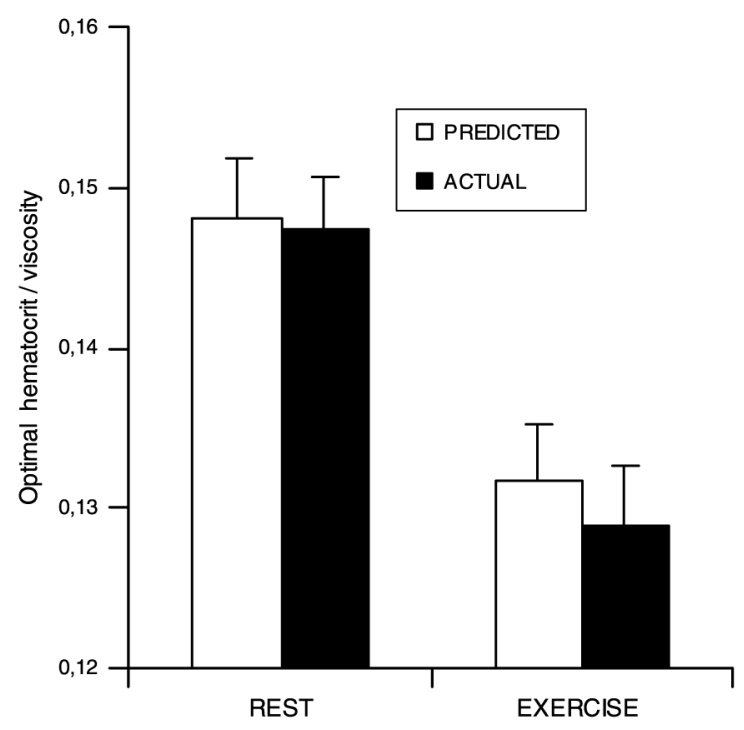

Fig. 4. Comparison between actual $\mathrm{h} / \eta$ and predicted $\mathrm{h} / \eta$ at rest and after exercise. The figure shows that actual $\mathrm{h} / \eta$ was lower than predicted $\mathrm{h} / \eta$ both before and after exercise (preexercise $p=0,005$; postexercise $p=0,02$ ).

\section{Discussion}

This study shows that (a) Quemada's equation yields a quite precise prediction of the $h / \eta$ that will actually be measured at high shear rate in blood samples when the curve plotting it against hematocrit is reconstructed from red cell rigidity and plasma viscosity values; (b) it also predicts quite well on the average the value of hematocrit which is thus close in these athletes from the 'optimal hematocrit' given by the theoretical approach; (c) there are however some discrepancies between predicted and actual hematocrit; (d) those discrepancies are explained by red cell rigidification during exercise.

The first interesting finding of this study is that Quemada's equation, a theoretical model that was not specifically developed for blood [27] provides a rather fine prediction of the "ideal" hematocrit with viscosity measurements performed at high shear rate. This further confirms the good accuracy of this classical equation.

However the finding of discrepancies which are correlated to the parameter " $\mathrm{k}$ " that, at high shear rate, measures red cell rigidity, should be pointed out. It may indicate that the two variables involved in viscoregulation are plasma viscosity and hematocrit, while red cell rheology is not a signal sensed for the homeostatic regulation of viscosity. It is known that an adaptative decrease in red cell rigidity 
conditions such as blood transfusion [29,36], sickle cell disease [10,37], or ischemic heart disease [28]. Concerning exercise physiology we were unable 20 years ago to evidence a relationship between $\mathrm{h} / \eta$ and maximal aerobic capacity although such a relationship could be theoretically expected $[3,4]$. However in a recent study in animals submitted to experimental alterations in hematocrit this relationship was clearly demonstrated [33]. The approach we propose in this paper may help to analyze more closely this parameter and its determinants in various physiological and pathophysiological situations.

This study also shows that in athletes the actual hematocrit is close of the theoretical 'optimal hematocrit' predicted by an equation of viscosity and suggests therefore, not only that this approach based on the $\mathrm{h} / \eta$ ratio is valid, but that in physiological conditions venous hematocrit is quite precisely set at its optimal value. It will be interesting to investigate whether in other physiological and pathologic contexts this remains true. The comparison between theoretical optimal and actual hematocrit values can expected to provide a means to explore viscoregulation.

\section{Conclusions}

Therefore, on the whole, this paper demonstrates in a sample of athletes that (a) Quemada's equation predicts $\mathrm{h} / \eta$ and the 'optimal hematocrit'; (b) this 'optimal hematocrit' is higher than actual hematocrit, but well correlated to it; (c) there are some discrepancies between predicted and actual hematocrit; (d) those discrepancies are explained by red cell rigidification during exercise which are taken into account by the model but are not likely to trigger viscoregulatory adaptations at least on the short term.

\section{References}

[1] M.-F. Aillaud, C. Poisson, M. Buonocore, M. Billerey, P. Lefevre and I. Juhan-vague, Etude du viscosimètre médical à chute de bille, Le Pharmacien Biologiste 159 (1985), 291-294.

[2] D. Bouix, C. Peyreigne, E. Raynaud, J.-F. Monnier, J.-P. Micallef and J.-F. Brun, Relationships among body composition, hemorheology and exercise performance in rugbymen, Clinical Hemorheology and Microcirculation 19 (1998), $245-254$.

[3] J.-F. Brun and E. Varlet-Marie, 2004, Unresolved issues in exercise hemorheology, EuroSummer School on Biorhelogy, Varna, Bulgaria, June 29th - July 2nd, 2003, Proceedings, Sofia, pp. 30-51.

[4] J.-F. Brun, E. Varlet-Marie, P. Connes and I. Aloulou, Hemorheological alterations related to training and overtraining, Biorheology 47(2) (2010), 95-115.

[5] J.-F. Brun, M. Guiraudou, C. Mardemootoo, A. Traoré, I. Raingeard, A. Chalançon and A. Avignon, Validation de la mesure segmentaire de la composition corporelle en comparaison avec la DEXA: Intérêt de la mesure de la masse grasse tronculaire, Science \& Sports 28 (2013), 158-162.

[6] A. Chabanel and M. Samama, Evaluation of a method to assess red blood cell aggregation, Biorheology 26 (1989), 785-797.

[7] S. Chien, Present state of blood rheology. In: Messmer K., Schmid-Schonbein H. (Eds) Hemodilution. Theoretical Basis and Clinical Application, Karger, Basel, (1972), pp 1-45.

[8] S. Chien, Hemorheology in clinical medicine, Clinical Hemorheology and Microcirculation 2 (1982), 137-142.

[9] X. Waltz, M.D. Hardy-Dessources, N. Lemonne, D. Mougenel, M.L. Lalanne-Mistrih, Y. Lamarre, V. Tarer, B. Tressières, M. Etienne-Julan, $\mathrm{O}$. Hue, and $\mathrm{Ph}$. Connes, Is there a relationship between the hematocrit-to-viscosity 
ratio and microvascular oxygenation in brain and muscle? Clinical Hemorheology and Microcirculation 2 (2015), 37-43.

[10] P. Connes, Y. Lamarre, M.D. Hardy-Dessources, N. Lemonne, X. Waltz, D. Mougenel, M. Mukisi-Mukaza, M.-L. Lalanne-Mistrih, V. Tarer, B. Tressières, M. Etienne-Julan and M. Romana, Decreased hematocrit-to-viscosity ratio and increased lactate dehydrogenase level in patients with sickle cell anemia and recurrent leg ulcers, PLoS One 8(11) (2013), e79680.

[11] V.A. Convertino, L.C. Keil, E.M. Bernauer and J.E. Greenleaf, Plasma volume, osmolality, vasopressin, and renin activity during graded exercise in man, Journal of Applied Physiology 50 (1981), 123-128.

[12] J.W. Crowell and E.E. Smith, Determinant of the optimal hematocrit, Journal of Applied Physiology 22 (1967), 501-504.

[13] L. Dintenfass, Blood viscosity, Hyperviscosity \& Hyperviscosaemia. Melbourne, MTP press, (1985), pp. 482

[14] J. Doffin, R. Perrault and G. Garnaud, Blood viscosity measurements in both extensional and shear flow by a falling ball viscometer, Biorheology 21(Suppl 1) (1984), 89-93.

[15] M. Donner, M. Siadat and J.-F. Stoltz, Erythrocyte aggregation: Approach by light scattering determination, Biorheology 25 (1988), 367-375.

[16] J. Dormandy, The dangerous red cell. Fahraeus Award Lecture, Clinical Hemorheology and Microcirculation 4 (1984), $115-132$.

[17] P. Gaehtgens, F. Kreutz and K.H. Albrecht, Optimal hematocrit for canine skeletal muscle during rhythmic isotonic exercise, European Journal of Applied Physiology and Occupational Physiology 41 (1979), 27-39.

[18] A. Gaudard, E. Varlet-Marie, F. Bressolle, J. Mercier and J.-F. Brun, Hemorheological correlates of fitness and unfitness in athletes: Moving beyond the apparent "paradox of hematocrit"? Clinical Hemorheology and Microcirculation 28(3) (2003), 161-173.

[19] J.E. Greenleaf, V.A. Convertino and G.R. Mangseth, Plasma volume during stress in man: Osmolality and red cell volume, Journal of Applied Physiology 47 (1979), 1031-1038.

[20] M. Guiraudou, L. Maimoun, J.-M. Dumas, M. Julia, I. Raingeard and J.-F. Brun, Composition corporelle mesurée par impédancemétrie segmentaire (BIAS) et performance de sprint chez les rugbymen/Body composition measured by bioimpedance segmental (BIAS) analysis and sprint performance in rugby players, Science \& Sports 30[N ${ }^{\circ}$ ] (2015), 298-302.

[21] A.C. Guyton and T.Q. Richardson, Effect of hematocrit on venous return, Circulation Research 9 (1961), 157.

[22] M. Hudak, R.C. Koehler, A.A. Rosenberg, R.J. Traystman and M.D. Jones Jr, Effect of hematocrit on cerebral blood flow, American Journal of Physiology 251 (1986), H63-H70.

[23] M.Y. Jaffrin and H. Morel, Body fluid volumes measurements by impedance: A review of bioimpedance spectroscopy (BIS) and bioimpedance analysis (BIA) methods, Medical Engineering \& Physics 30(10) (2008), 1257-1269.

[24] P. Mills, D. Quemada and J. Dufaux, Etude de la cinétique d'agrégation érythrocytaire dans un écoulement Couette, Revue de Physique Appliquée (1980) 15, 1357-1366.

[25] N. Nemeth, T. Alexy, A. Furka, O.K. Baskurt, H.J. Meiselman, I. Furka and I. Miko I, Inter-species differences in hematocrit to blood viscosity ratio, Biorheology 46(2) (2009), 155-165.

[26] B. Pignon, S. Muller, D. Jolly, M. Siadat, E. Petitfrere, B. Vessel, M. Donner, G. Potron and J.-F. Stoltz, Validation d'une méthode d'approche de l'agrégation érythrocytaire par rétrodiffusion laser. In: Hémorhéologie et agrégation érythrocytaire. Volume 2, applications cliniques J.F. Stoltz (Eds.) Paris: Editions Médicales Internationales, (1988), pp. 65-74.

[27] D. Quemada, Rheology of concentrated disperse systems. II. A model of non newtonian shear viscosity in steady flows, Rheologyca Acta 17 (1978), 632-642.

[28] B. Sandor, A. Nagy, A. Toth, M. Rabai and B. Mezey, Effects of moderate aerobic exercise training on hemorheological and laboratory parameters in ischemic heart disease patients, PLoS One 9(10) (2014), e110751.

[29] E.A. Schmalzer, J.O. Lee, A.K. Brown, S. Usami and S. Chien, Viscosity of mixtures of sickle and normal red cells at varying hematocrit levels. Implications for transfusion, Transfusion 27(3) (1987), 228-233.

[30] H. Schmid-Schönbein, E. Volger and H.J. Klose, Microrheology and light transmission of blood III: The velocity of red cell aggregate formation, Pflugers Archiv European Journal of Physiology 254 (1975), 299-317.

[31] H. Schmid-Schönbein, M. Foerster, H. Heidtmann, J. Hektor, J. Hoymann, R. Grebe and T. Kirschkamp, "Percolation theory as the rational basis of clinical hemorheology: The role of "abnormal" flow behaviour of blood elements on the homogeneity of perfusion, gas exchange and metabolism”, Biorheology 39(N॰5), (2002) (abstract).

[32] P. Snabre, M. Bitbol and P. Mills, Cell disaggregation behavior in shear flow, Biophysical Journal 51 (1987), 795-807.

[33] H. Stark and S. Schuster, Comparison of various approaches to calculating the optimal hematocrit in vertebrate, Journal of Applied Physiology 113(3) (2012), 355-367. 
[34] J.F. Stoltz, M. Donner and S. Muller, Introduction de la notion de profil hémorhéologique.: "Hémorhéologie et Facteurs de Risque", 7e Réunion Conjointe de la Société d'Hémorhéologie de l'Ouest et de la Société de Biorhéologie de Langue Française. Rennes (France), Bidet J.-M., Boudart D., Delamaire M., Durand F. (Eds) (1990), pp. 12-25.

[35] J.F. Stoltz and M. Donner, New trends in clinical hemorheology: An introduction to the concept of the hemorheological profile, Schweizerische Medizinische Wochenschrift (Suppl 43) (1991), 41-49.

[36] A. Tamas, E. Pais, J.K. Armstrong, H.J. Meiselman, C.S. Johnson and T.C. Fisher, Rheologic behavior of sickle and normal red blood cell mixtures in sickle plasma: Implications for transfusion therapy, Transfusion 46 (2006), 912-918.

[37] J. Tripette, A. Tamas, M.-D. Hardy-Dessources, D. Mougenel, E. Beltan, T. Chalabi, R. Chout, M. Etienne-Julan, O. Hue, H.J. Meiselman and P. Connes, Red blood cell aggregation, aggregate strength and oxygen transport potential of blood are abnormal in both homozygous sickle cell anemia and sickle-hemoglobin C disease, Haematologica 94(8) (2009), 1060-1065.

[38] R.A. Usha and J. Anderson, Erythrocyte deformability and lung segmental vascular resistance: Effect of hematocrit, Journal of Applied Physiology 70 (1991), 1386-1392.

[39] W. Van Beaumont, J.E. Greenleaf and L. Juhos, Disproportional changes in hematocrit, plasma volume and proteins during exercise and bed rest, Journal of Applied Physiol 33 (1972), 55-61.

[40] J. Vogel, I. Kiessling, K. Heinicke, T. Stallmach, P. Ossent, O. Vogel, M. Aulmann, T. Frietsch, H. Schmid-Schönbein, W. Kuschinsky and M. Gassmann, Transgenic mice overexpressing erythropoietin adapt to excessive erythrocytosis by regulating blood viscosity, Blood $\mathbf{1 0 2}(6)$ (2003), 2278-2284. 